\title{
Gold Nanoparticles with Self-Assembled Cysteine Monolayer Coupled to Nitrate Reductase in Polypyrrole Matrix Enhanced Nitrate Biosensor
}

\author{
Thangamuthu Madasamy ${ }^{1}$, Manickam Pandiaraj ${ }^{1}$, Anantha Koteswararao Kanugula ${ }^{3}$, \\ Seenivasan Rajesh ${ }^{1}$, Kalpana Bhargava ${ }^{2}$, Niroj Kumar Sethy ${ }^{2}$, Srigiridhar Kotamraju ${ }^{3}$, and \\ Chandran Karunakaran ${ }^{1, *}$ \\ ${ }^{1}$ Biomedical Research Laboratory, Department of Chemistry, VHNSN College, Virudhunagar 626001, Tamil Nadu, India \\ ${ }^{2}$ Peptide and Proteomics Division, DIPAS, DRDO, Delhi 110054, India \\ ${ }^{3}$ Center for Chemical Biology, CSIR-Indian Institute of Chemical Technology, Hyderabad 500607, India
}

We have developed here a novel, highly sensitive and selective nitrate $\left(\mathrm{NO}_{3}^{-}\right)$biosensor by covalent immobilization of nitrate reductase (NaR) in self-assembled monolayer (SAM) of cysteine on gold nanoparticles (GNP)-polypyrrole (PPy) modified platinum electrode. Incorporation of GNP in highly microporous PPy matrix was confirmed by morphological scanning electron microscope (SEM) images. The electrochemical behavior of the NaR modified electrode exhibited the characteristic reversible redox peaks at the potential, -0.76 and $-0.62 \mathrm{~V}$ versus $\mathrm{Ag} / \mathrm{AgCl}$. Further, the GNP-PPy nanocomposite enhanced the current response by 2-fold perhaps by enhancing the immobilization of $\mathrm{NaR}$ and also direct electron transfer between the deeply buried active site and the electrode surface. The common biological interferences like ascorbic acid, uric acid were not interfering with the $\mathrm{NO}_{3}^{-}$measurement at low concentration levels. This biosensor showed a wide linear range of response over the concentration of $\mathrm{NO}_{3}^{-}$from $1 \mu \mathrm{M}$ to $1 \mathrm{mM}$, with higher sensitivity of $84.5 \mathrm{nA}_{\mu \mathrm{M}^{-1}}$ and a detection limit of $0.5 \mu \mathrm{M}$. Moreover, the $\mathrm{NO}_{3}^{-}$level present in the nitrate-rich beetroot juice and the $\mathrm{NO}_{3}^{-}$ release from the lipopolysaccharide treated human breast cancer cells were estimated.

KEYWORDS: Beetroot Juice, Cancer Cells, Gold Nanoparticles, Nitrate Reductase, Nitrate Biosensor, Direct Electron Transfer.

\section{INTRODUCTION}

Inorganic nitrate $\left(\mathrm{NO}_{3}^{-}\right)$anion is generally believed to be an inert oxidative product of nitric oxide (NO) metabolism and potentially toxic for food chain. ${ }^{1}$ However, recent research reports suggest existence of an alternate NitrateNitrite-NO pathway promoting NO bioavailability and signaling during ischemia and hypoxia. ${ }^{2}$ Administration of exogenous $\mathrm{NO}_{3}^{-}$to human and several animal models reportedly promotes NO-like bioactivity and regulates biological activities like reduction of blood pressure, vasodilation, cytoprotection, cardioprotection, protection from ischemia-reperfusion injury as well as promotes exercise capacity. ${ }^{3-5}$ Interestingly, the vegetables like beetroot, spinach, and lettuce along with cured meat in our everyday diet is a major source of inorganic nitrate. ${ }^{6}$ Recent

\footnotetext{
*Author to whom correspondence should be addressed.

Email: ckaru2000@gmail.com

Received: 22 June 2012

Accepted: 6 August 2012
}

perspective observational investigations have also shown that higher intake of nitrate-rich fruits and vegetables are associated with reduced risk of coronary and ischemic heart diseases. ${ }^{7,8}$ Hence, the measurement of $\mathrm{NO}_{3}^{-}$level present in the beetroot juice give a supporting information to prove the natural remedy effect of beetroot juice against cardiovascular diseases and blood pressure. Moreover, the measurement of $\mathrm{NO}_{3}^{-}$release during lipopolysaccharide (LPS) induced apoptosis in cancer cells and macrophages give an idea to know the molecular mechanisms by which LPS exert cytotoxicity. ${ }^{9}$ So, the determination of $\mathrm{NO}_{3}^{-}$is increasingly important in biology and medicine.

In the literature, various methods have been reported for the determination of $\mathrm{NO}_{3}^{-}$including spectrophotometry, ${ }^{10,11}$ fluorescence, ${ }^{12,13}$ ion-exchange chromatography. ${ }^{14}$ These methods were time consuming and not sufficiently specific. Recently, electrochemical biosensor techniques are proved to be powerful tools due to their advantages of simplicity, portability, inexpensive and fast analysis in combination with high selectivity. ${ }^{15-20}$ 
The enzymatic ${ }^{21,22}$ and non-enzymatic ${ }^{23,24}$ electrochemical methods have been reported for the determination of $\mathrm{NO}_{3}^{-}$. Among these, the enzymatic method has been widely performed using nitrate reductase $(\mathrm{NaR})$. $\mathrm{NaR}$ is a multidomain enzyme containing flavin adenine dinucleotide (FAD), two heme-Fe and molybdopterin, which catalyzes the two electron reduction of $\mathrm{NO}_{3}^{-}$to $\mathrm{NO}_{2}^{-} \cdot{ }^{25}$

$$
\mathrm{NO}_{3}^{-}+\beta-\mathrm{NAD}(\mathrm{P}) \mathrm{H} \stackrel{\mathrm{NaR}}{\longrightarrow} \mathrm{NO}_{2}^{-}+\mathrm{H}_{2} \mathrm{O}+\beta-\mathrm{NAD}(\mathrm{P})
$$

The stable immobilization of an enzyme on an electrode surface with complete retention of its biological activity is a crucial problem for the commercial development of biosensors. During the last decades, conducting polymers have attracted much interest as a suitable matrix for the entrapment of enzymes. ${ }^{26}$ Among the conducting polymers, polypyrrole (PPy) was widely used owing to its high electrical conductivity, good stability and easy to fabricate on the electrode surface. ${ }^{27}$ Further, modification of electrode surface with gold nanoparticles (GNP) provides a microenvironment similar to that of the redox proteins in the native systems due to its large surface-to-volume ratio, increased surface activity and electronic properties. ${ }^{28}$ Also, thiols on GNP forms highly ordered and stable selfassembled monolayer (SAM). These well ordered monolayers offer the possibility to covalently fix proteins close to an electrode surface, further the electrical wiring of PPy/GNP nanocomposite functioning as electron conducting pathways between the deeply burried prosthetic groups and the electrode.

Hence, in this work, we have covalently coupled the $\mathrm{NaR}$, a multidomain enzyme to the SAM of cysteine on GNP in PPy matrix. This NaR modified electrode exhibited the higher sensitivity because of the facilitated electron transfer and enhanced loading of $\mathrm{NaR}$ at the SAM-GNP-PPy-Pt electrode. For the first time, we have estimated here the $\mathrm{NO}_{3}^{-}$level present in the beetroot juice using this biosensor and validated with the griess method. Further, the $\mathrm{NO}_{3}^{-}$release from LPS treated human breast cancer cells was also estimated.

\section{EXPERIMENTAL DETAILS}

\subsection{Reagents}

Nitrate reductase from Aspergillus niger, chloroauric acid trihydrate $\left(\mathrm{HAuCl}_{4} \cdot 3 \mathrm{H}_{2} \mathrm{O}\right), \beta$-NADPH, sulphanilic acid, $N$-(1-naphthyl)ethylenediamine dihydrochloride, cysteine, sodium ascorbate, uric acid, sodium hydrogen phosphate, disodium hydrogen phosphate, pyrrole, $\mathrm{NaNO}_{3}, \mathrm{KCl}$ and LPS were obtained from Sigma Company (Milwaukee, WI, USA). Nitrate supplement beetroot juice was obtained from Defence Food Research Laboratory, Mysore, India. MCF-7 breast cancer cells were obtained from ATCC. All the solutions were prepared with doubly distilled water.

\subsection{MCF-7 Cell Culture}

MCF-7 cells were grown in $10 \%$ minimum essential medium (MEM) containing 10\% fetal bovine serum (FBS), l-glutamine (4 mmol L $\left.{ }^{-1}\right)$, penicillin (100 units $\left.\mathrm{mL}^{-1}\right)$ and streptomycin $(100 \mu \mathrm{g} \mathrm{mL}-1)$, and incubated at $37^{\circ} \mathrm{C}$ in a humidified atmosphere of $5 \% \mathrm{CO}_{2}$ and $95 \%$ air.

\subsection{Instrumentations}

All the electrochemical experiments were performed using CHI 1200B electrochemical workstation (CHI, USA) with a conventional three electrode system which consisted of an $\mathrm{Ag} / \mathrm{AgCl}$ wire as reference electrode, a Pt wire as auxiliary or counter electrode and a Pt electrode with $\mathrm{NaR}$ immobilized in SAM-GNP-PPy as the working electrode. The size of Pt wire working electrode was $0.5 \mathrm{~mm}$ in diameter. Spectrophotometric studies were carried out using shimadzu 1800 UV spectrophotometer (Shimadzu scientific instruments Inc.). The SEM morphological images of GNP-PPy-Pt, PPy-Pt and bare Pt electrodes were obtained using a FEI Quanta FEG 200-High Resolution Scanning Electron Microscope (FEI Co., Netherlands).

\subsection{Synthesis of Gold Nanoparticles (GNP)}

GNP was prepared as per earlier report ${ }^{29}$ by adding $40 \mathrm{ml}$ of $0.1 \mathrm{M}$ solution of $\mathrm{HAuCl}_{4} \cdot 3 \mathrm{H}_{2} \mathrm{O}$ and $60 \mathrm{ml}$ of $0.1 \mathrm{M}$ D-glucose to about $2 \mathrm{ml}$ of $0.2 \%$ soluble starch followed by $15 \mathrm{ml}$ of $1 \mathrm{M} \mathrm{NaOH}$. The solution remained colorless for the initial $30 \mathrm{~min}$, following which it turned red slowly, indicating the formation of GNP. The GNP was stable for several months, as confirmed by its surface plasmon resonance peak at around $525 \mathrm{~nm}$.

\subsection{Construction of NaR-SAM-GNP-PPy-Pt Electrode}

\subsubsection{Pyrrole Electropolymerization}

Prior to electropolymerization, the electrode was polished with alumina powder (size 0.05 and $1.0 \mu \mathrm{m}$ ) until to get a highly shining surface and washed twice with double distilled water. Finally, the electrode was cleaned in $1 \mathrm{M} \mathrm{H}_{2} \mathrm{SO}_{4}$ by cycling the potential from -200 to $+1450 \mathrm{mV}$ versus $\mathrm{Ag} / \mathrm{AgCl}$ until to attain reproducible cyclic voltammograms (CVs) and then washed with double distilled water. PPy films were electropolymerized and electroadsorbed ${ }^{30}$ on to the bare $\mathrm{Pt}$ electrode from a deaerated solution of $0.4 \mathrm{M}$ pyrrole using $0.1 \mathrm{M}$ $\mathrm{KCl}$ as supporting electrolyte, at the potential between 0.0 and $+0.9 \mathrm{~V}$ versus $\mathrm{Ag} / \mathrm{AgCl}$ with a scan rate of $50 \mathrm{mV} \mathrm{s}^{-1}$, for 10 complete cycles. ${ }^{31}$ The pyrrole polymerization was carried out under argon atmosphere at room temperature. 


\subsubsection{Formation of the SAM-GNP-PPy Nanocomposite and Immobilization of NaR}

The obtained PPy-Pt electrode was immersed in GNP solution for $10 \mathrm{~h}$ and then carefully rinsed with double distilled water. GNP was incorporated into the microporous PPy matrix perhaps via the electrostatic attraction. ${ }^{32}$ Further, the GNP-PPy-Pt electrode modified with the SAM of cysteine was prepared by dipping the previously GNP incorporated PPy-Pt electrode into a $1 \mathrm{mM}$ cysteine solution for $20 \mathrm{~min}$ and rinsed with double distilled water to remove the non-chemisorbed cysteine. Then, $5 \mu \mathrm{L}$ of $\mathrm{NaR}\left(0.2 \mathrm{~g} \mathrm{~mL}^{-1}\right)$ enzyme solution was dropped onto SAM-GNP-PPy-Pt modified electrode. After that, the electrode was left for $24 \mathrm{~h}$ at $4{ }^{\circ} \mathrm{C}$. During this process, the NaR is covalently coupled on SAM-GNP-PPy-Pt electrode. The preparation of this modified electrode is shown in Scheme 1. This NaR modified electrode was immersed in $0.1 \mathrm{M}$ PBS to remove the loosely adsorbed $\mathrm{NaR}$ and was stored at $4{ }^{\circ} \mathrm{C}$ when not in use.

\section{RESULTS AND DISCUSSION}

The majority of sensor devices utilize many conducting polymers (polyaniline, polypyrrole and polyacetylene) with definite roles, either in the sensing mechanism or through immobilizing the species responsible for sensing of the analyte component. In this study, we have incorporated GNP in the highly porous PPy matrix on the electrode surface. Further, SAM of cysteine on GNP in PPy matrix enhanced the immobilization of $\mathrm{NaR}$ to achieve high sensitivity for the determination of $\mathrm{NO}_{3}^{-}$. In order to test the performance of the developed $\mathrm{NO}_{3}^{-}$biosensor, sensitivity, life time, scan rate, $\mathrm{pH}$ and selectivity were investigated.

\subsection{Characterization of GNP by UV-Visible Spectroscopy}

The typical UV-visible absorption spectrum of the synthesized GNP exhibited $\lambda_{\max }$ at $525 \mathrm{~nm}$. The peak intensity and position of the surface plasmon absorption band was earlier reported to be dependent on the size and geometry of the metal nanoparticles as well as the medium surrounding the particles. It was reported that the spherical particles with diameters around 6-10 nanometers characterized by HR-TEM showed a strong absorption peak in the visible region of the UV-visible spectrum. ${ }^{29}$ Thus, the observed peak at $525 \mathrm{~nm}$ here clearly revealed the formation of GNP.

\subsection{Morphological Characterization of Electrodes Using SEM}

Figures 1(a)-(c) show the SEM morphological images of bare Pt, PPy-Pt and GNP-PPy-Pt electrodes respectively. Figure 1(b) reveals the typical highly porous morphology of PPy on Pt electrode surface. This high porous nature of PPy perhaps provides much larger surface area to incorporate more GNP and hence NaR at the electrode surface. Further, the SEM of GNP-PPy-Pt (Fig. 1(c)) electrode shows the gold nanoparticles were distributed on the PPy matrix.

\subsection{Electrochemical Characterization of the Modified Electrodes}

Figure 2 shows the typical $\mathrm{CV}$ obtained for the bare $\mathrm{Pt}$ (curve a), PPy-Pt (curve b), GNP-PPy-Pt (curve c), NaRPPy-Pt (curve d) and NaR-SAM-GNP-PPy-Pt (curve e) electrodes at a scan rate of $50 \mathrm{mV} \mathrm{s}^{-1}$ in $0.1 \mathrm{M}$ PBS at $\mathrm{pH}$ 7.0. The broad peaks were observed on the $\mathrm{CV}$ range of $-0.9 \mathrm{~V}$ to $-0.3 \mathrm{~V}$ for the PPy-Pt and GNP-PPy-Pt electrodes perhaps due to the complex redox process of $\mathrm{PPy}^{33}$ and also high capacitive currents. ${ }^{34}$ However, the CV of NaR immobilized on both the PPy-Pt and SAM-GNP-PPyPt electrodes exhibited well-defined reversible redox peaks at -0.76 and $-0.62 \mathrm{~V}$ versus $\mathrm{Ag} / \mathrm{AgCl}$ with decreased capacitive currents. When enzyme was adsorbed on the electrode surface, the capacitive currents in the doublelayer regions decreased because the proteinaceous layer
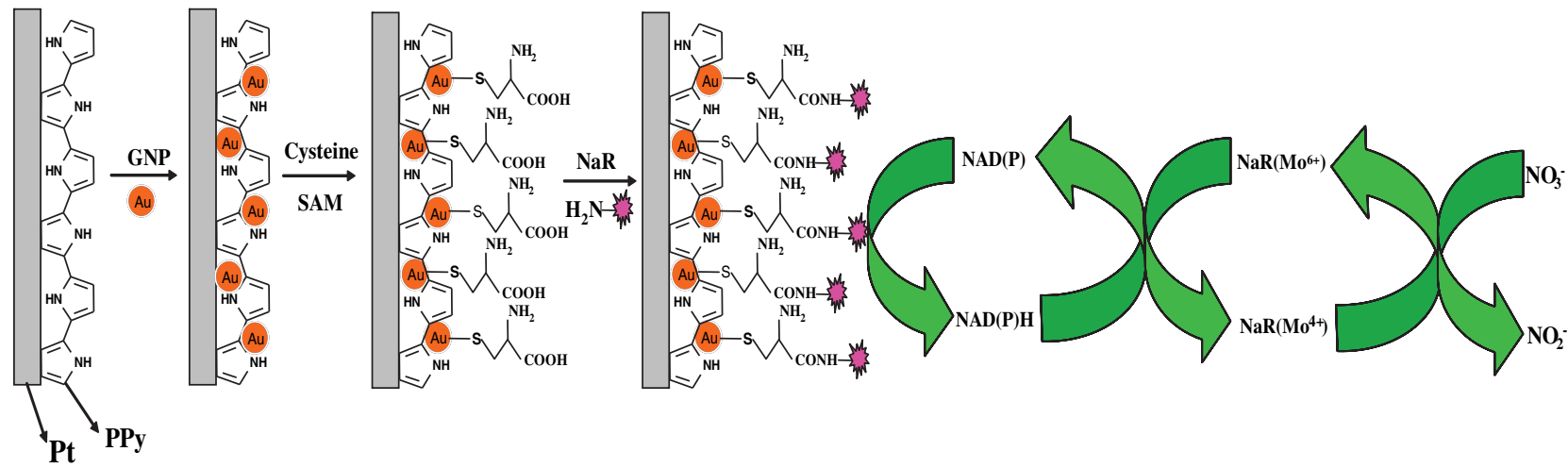

Scheme 1. Schematic representation of the preparation of NaR-SAM-GNP-PPy-Pt electrode and the illustration of the reactions during the determination of $\mathrm{NO}_{3}^{-}$. 

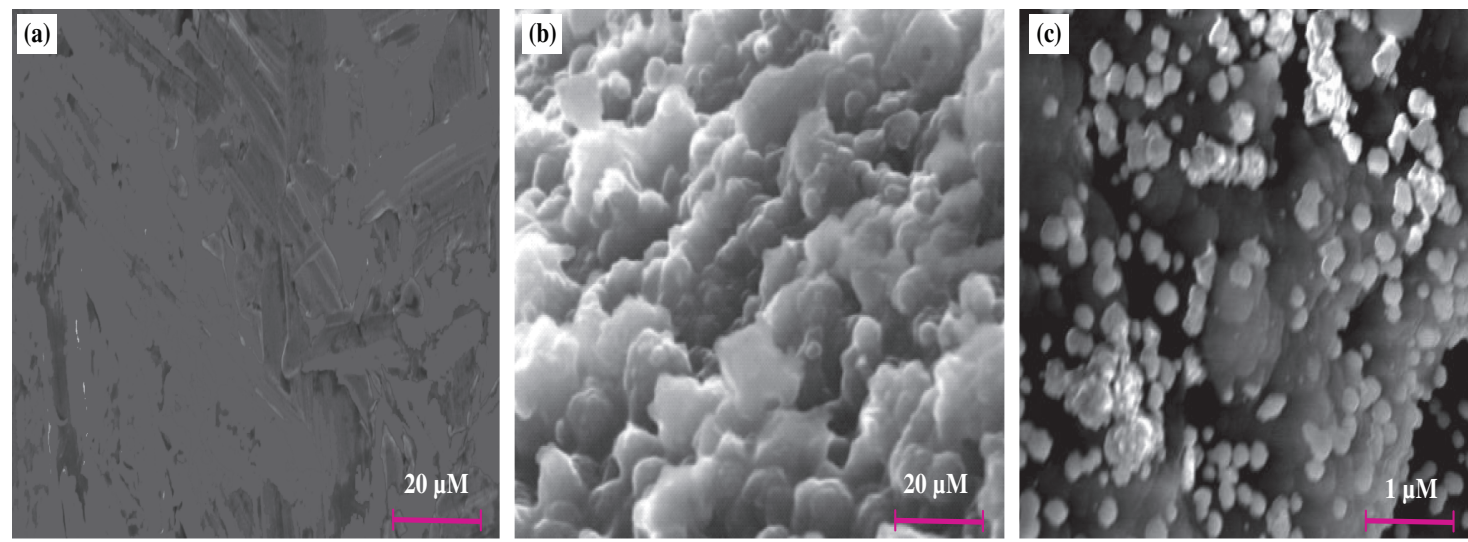

Fig. 1. SEM micrographs of (a) bare Pt, (b) PPy-Pt and (c) GNP-PPy-Pt electrodes.

was formed. This interaction with the electrical double layer (Helmholtz double layer) at the electrode severely hindered the electron transfer rates between the electrode surface and the electrolyte. ${ }^{34}$ Consequently, the Helmholtz distance (between the Helmholtz layer and the electrode) increased; hence the electrical double layer may be forced away from the electrode surface. ${ }^{35}$ So, the capacitive currents obtained for the NaR modified electrode decreased (curve $\mathrm{d}$ and curve e) when compared to without $\mathrm{NaR}$ (curve $\mathrm{b}$ and curve $\mathrm{c}$ ). The observed reversible redox peaks are further attributed to the Mo(IV/VI) complex moiety of $\mathrm{NaR}$ in agreement with the previously reported data. ${ }^{25}$ It clearly reveals that the NaR was immobilized on the electrode surface.

It is further evident from the Figure 2 that the NaRSAM-GNP-PPy-Pt electrode (curve e) shows increase in current than the NaR-PPy-Pt electrode (curve d). This is perhaps due to the large number of $\mathrm{NaR}$ molecules firmly coupled on the SAM of cysteine on GNP in PPy matrix and also the facilitated electron transfer between

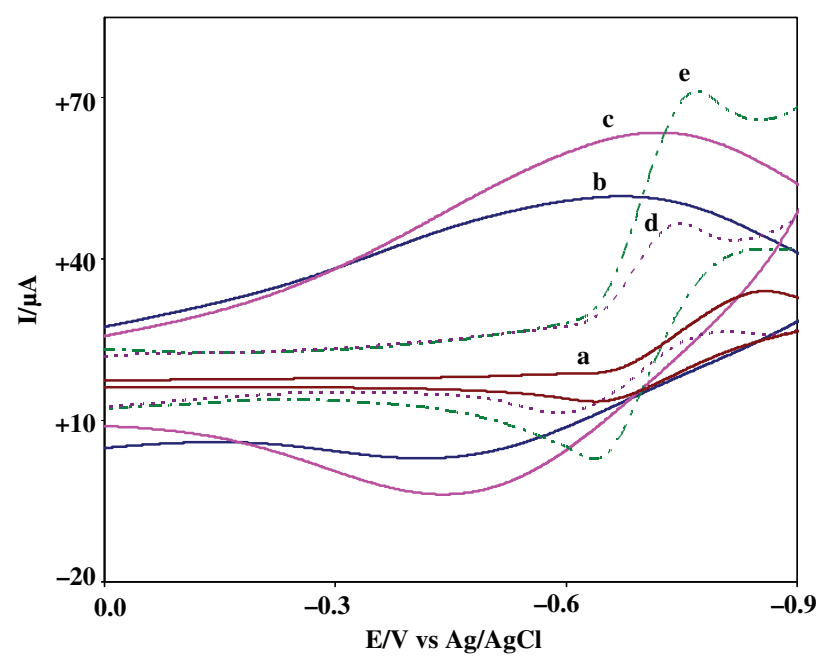

Fig. 2. Typical CV response of (a) bare Pt, (b) PPy-Pt, (c) GNP-PPy$\mathrm{Pt}$, (d) NaR-PPy-Pt and (e) NaR-SAM-GNP-PPy-Pt electrodes in $0.1 \mathrm{M}$ PBS (pH 7.0) at scan rate: $50 \mathrm{mV} \mathrm{s}^{-1}$ versus $\mathrm{Ag} / \mathrm{AgCl}$. the electrode and the active site of the NaR. The welldefined reversible redox peaks obtained due to $\mathrm{NaR}$ and the current observed were stable; for instance, it remained essentially unchanged when the potential scan was continuously repeated at $50 \mathrm{mV} \mathrm{s}^{-1}$ for $10 \mathrm{~min}$.

\subsection{Electrochemical Response to $\mathrm{NO}_{3}^{-}$}

Figure 3 shows the electrochemical response of the bare Pt, NaR-PPy-Pt and NaR-SAM-GNP-PPy-Pt electrodes in the absence (a, b and d) and presence ( $c$ and e) of $500 \mu \mathrm{M}$ $\mathrm{NO}_{3}^{-}$in 0.1 MPBS ( $\mathrm{pH} 7.0$ ) measured at the scan rate of $50 \mathrm{mV} \mathrm{s}^{-1}$ versus $\mathrm{Ag} / \mathrm{AgCl}$. After the addition of $\mathrm{NO}_{3}^{-}$, the current response at the bare $\mathrm{Pt}$ electrode is same as without $\mathrm{NO}_{3}^{-}$(data not shown). However, the current is significantly increased in both the NaR-PPy-Pt (curve c) and NaR-SAM-GNP-PPy-Pt (curve e) electrodes cathodically as well as anodically. It is due to the enhanced electrocatalytic activity of the NaR-modified electrodes based

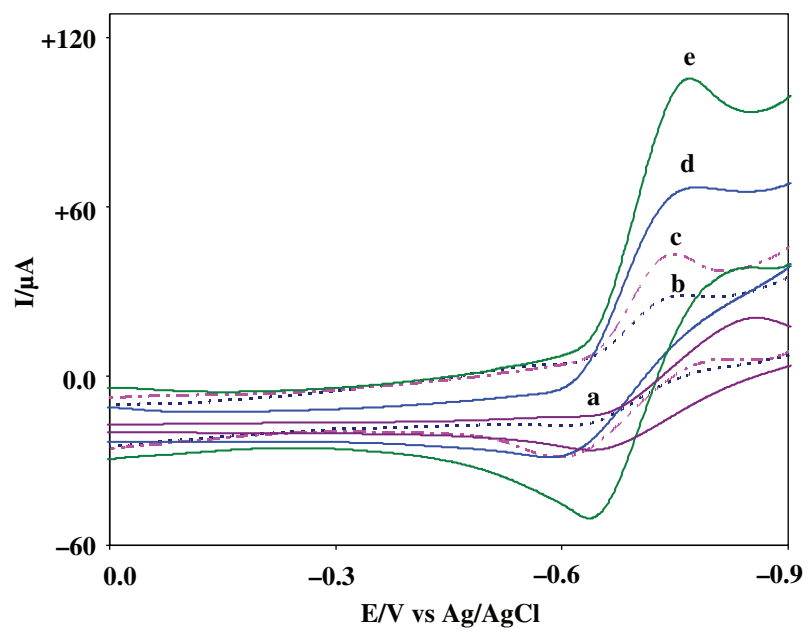

Fig. 3. Electrochemical response of bare Pt, NaR-PPy-Pt and NaRSAM-GNP-PPy-Pt electrodes in the absence ( $\mathrm{a}, \mathrm{b}$ and $\mathrm{d}$ ) and presence (c and e) of $500 \mu \mathrm{M} \mathrm{NO}_{3}^{-}$in $0.1 \mathrm{M} \mathrm{PBS}$ at scan rate: $50 \mathrm{mV} \mathrm{s}^{-1}$ versus $\mathrm{Ag} / \mathrm{AgCl}$. 
on the intrinsic specificity of the $\mathrm{NaR}$ which catalyzes the reduction of $\mathrm{NO}_{3}^{-}$to $\mathrm{NO}_{2}^{-}$via a cyclic redox reaction of its $\mathrm{Mo}(\mathrm{IV} / \mathrm{VI})$ complex moiety (Scheme 1).

\subsection{Effect of Gold Nanoparticles}

Figure 4 compares the CV's of NaR-SAM-GNP-PPy$\mathrm{Pt}$ and NaR-PPy-Pt electrodes in 0.1 M PBS containing $200 \mu \mathrm{M} \mathrm{NO}_{3}^{-}$. It is obviously seen that the current response of the NaR-SAM-GNP-PPy-Pt electrode is 2-fold $(40 \mu \mathrm{A})$ greater than that of the NaR-PPy-Pt electrode at $-0.76 \mathrm{~V}$. This observed increase in current suggest that the SAM of cysteine on GNP perhaps provided more surface area to couple $\mathrm{NaR}$ effectively and also a desirable orientation, environment to facilitate the direct electron transfer between the active site of the $\mathrm{NaR}$ and the base electrode.

\subsection{Effect of pH and Scan Rate}

The electrochemical behavior of the $\mathrm{NO}_{3}^{-}$biosensor was studied in the $\mathrm{pH}$ range of 3.0-10.0. For the $\mathrm{pH}$ study, a mixture of disodium hydrogen phosphate and citric acid buffer was used. The current response was decreased from $\mathrm{pH} 7.0-3.0$ and also from $\mathrm{pH} 7.0-10.0$, perhaps due to the denaturation of immobilized $\mathrm{NaR}$. However, the maximum current response was observed at pH 7.0 (Fig. 5(A)).

Further, the influence of the scan rate on the CV performance of the NaR-SAM-GNP-PPy-Pt electrode was investigated (Fig. 5(B)). It was found that the cathodic peak currents increased linearly with increasing the scan rate from 50 to $250 \mathrm{mV} \mathrm{s}^{-1}$ and also the characteristic CV remains unchanged on successive potential scanning upto $250 \mathrm{mV} \mathrm{s}^{-1}$. This indicates the favorable orientation of $\mathrm{NaR}$ at the SAM-GNP-PPy-Pt electrode leading to a facilitated electron transfer of $\mathrm{NaR}$.

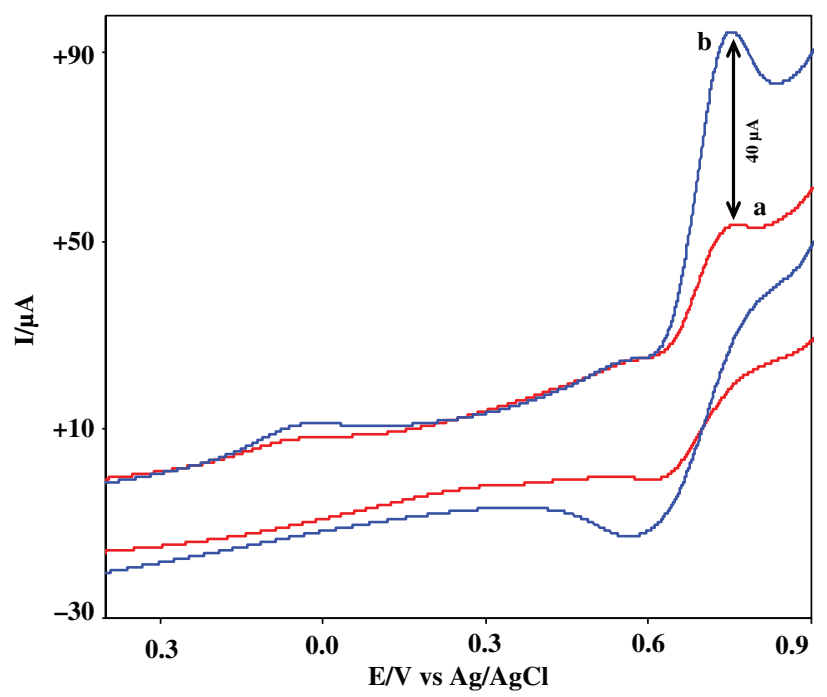

Fig. 4. Typical CV response of (a) NaR-PPy-Pt and (b) NaR-SAMGNP-PPy-Pt electrodes in $0.1 \mathrm{M}$ PBS containing $200 \mu \mathrm{M} \mathrm{NO}_{3}^{-}$at scan rate: $50 \mathrm{mV} \mathrm{s}^{-1}$ versus $\mathrm{Ag} / \mathrm{AgCl}$.
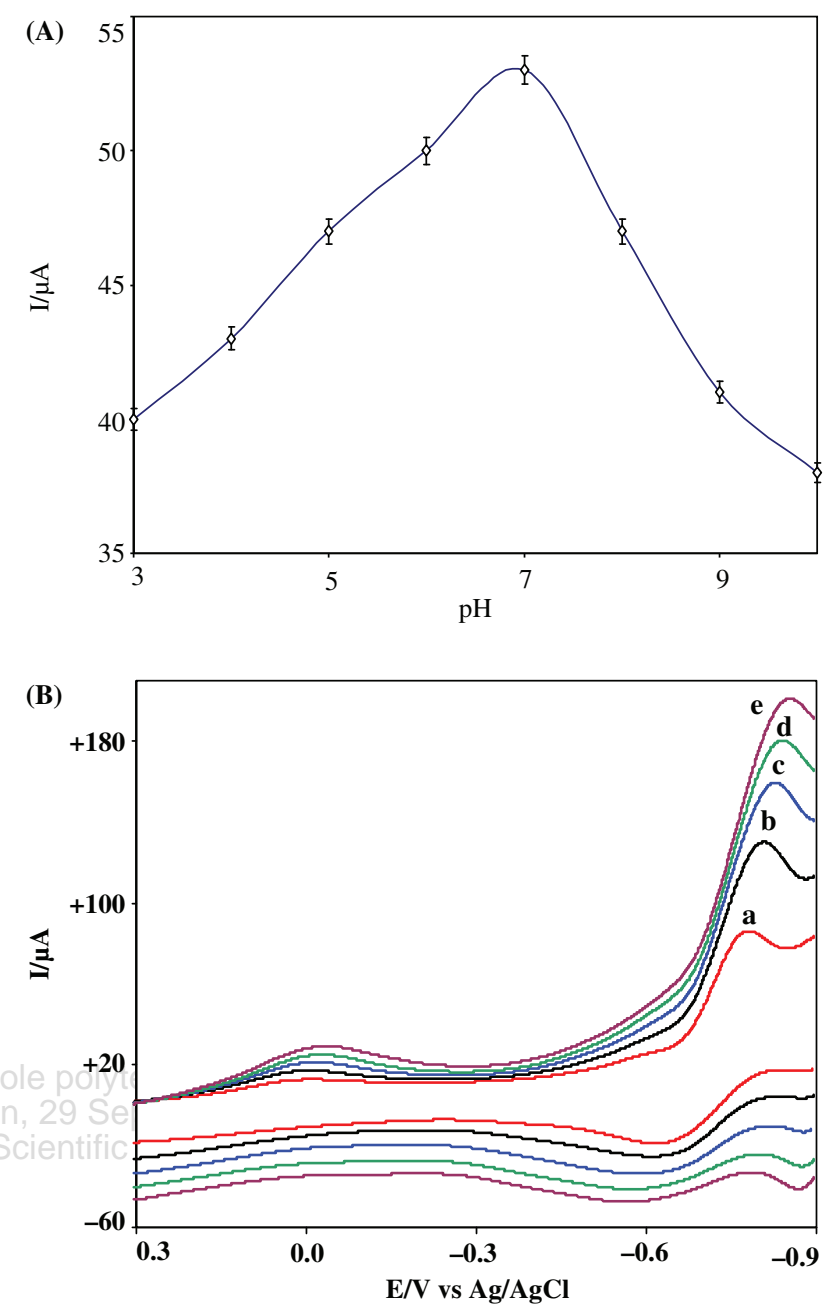

Fig. 5. (A) Effect of $\mathrm{pH}$ on peak current of NaR-SAM-GNP-PPy-Pt electrode in $0.1 \mathrm{M}$ PBS at scan rate: $50 \mathrm{mV} \mathrm{s}^{-1}$ versus $\mathrm{Ag} / \mathrm{AgCl}$. Each point represents the average of three measurements. (B) Effect of increasing scan rate from 50 to $250 \mathrm{mV} \mathrm{s}^{-1}$ on NaR-SAM-GNP-PPy-Pt electrode in $0.1 \mathrm{M}$ PBS containing $200 \mu \mathrm{M}$ of $\mathrm{NO}_{3}^{-}$solution.

\subsection{Linearity, Selectivity, Stability and Reproducibility}

Typical CVs were obtained for several concentrations of $\mathrm{NO}_{3}^{-}$in $0.1 \mathrm{M} \mathrm{PBS}$ at $50 \mathrm{mV} \mathrm{s}^{-1}$ for NaR-SAM-GNPPPy-Pt and are shown in Figure 6(A). The observed cathodic currents versus $\mathrm{NO}_{3}^{-}$concentrations are plotted as shown in Figure 6(B). The calibration curve thus obtained for NaR-SAM-GNP-PPy-Pt electrode exhibits a linear range of response for the $\mathrm{NO}_{3}^{-}$concentrations from $1 \mu \mathrm{M}$ to $1 \mathrm{mM}\left(r^{2}=0.9837, n=3\right)$ with a detection limit of $0.5 \mu \mathrm{M}$.

Moreover, the NaR-SAM-GNP-PPy-Pt electrode shows the excellent electroanalytical performance; for instance, wider linear detection range and especially high sensitivity, compared to the other reported $\mathrm{NO}_{3}^{-}$biosensors (Table I).

It is well-known that coexisting biological substrates viz ascorbic acid (AsA) and uric acid (UA) present at high 

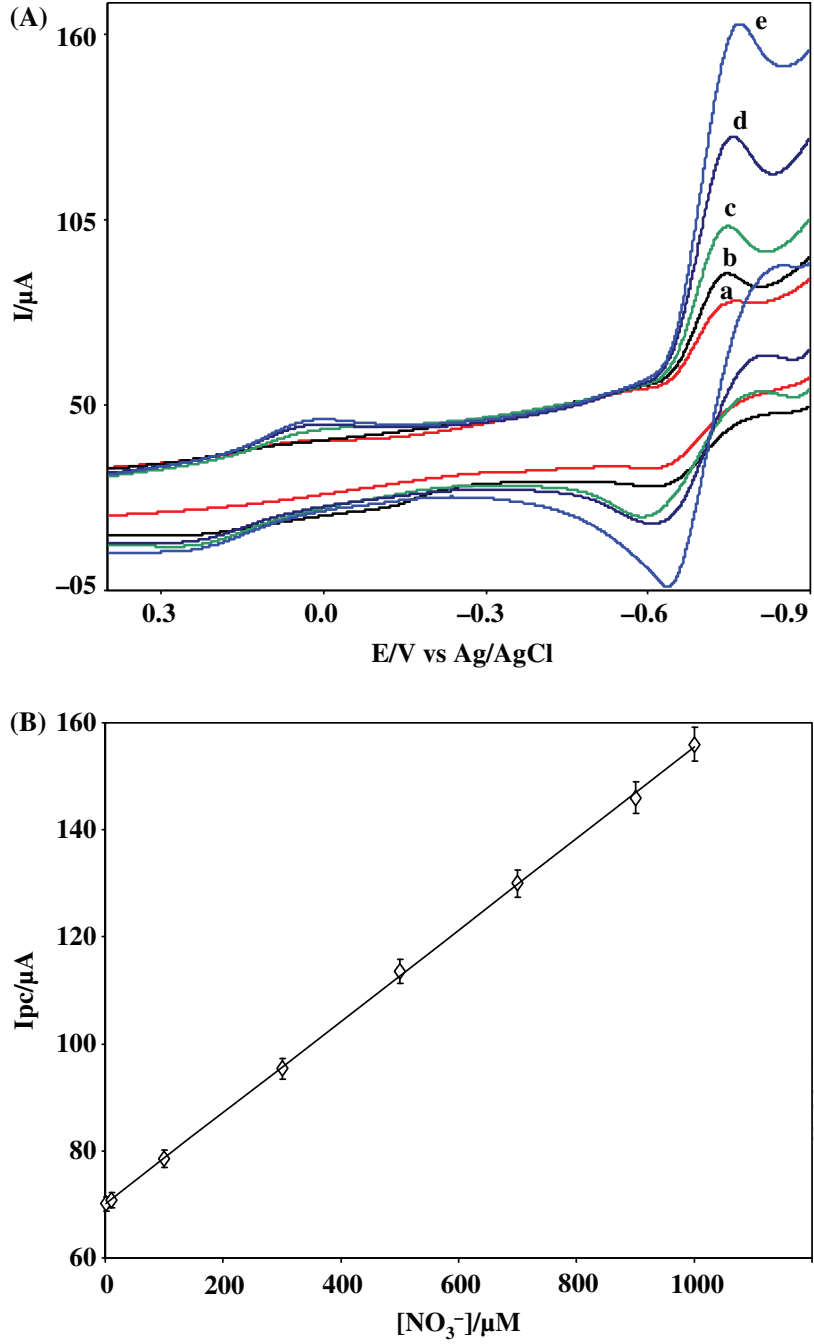

Fig. 6. (A) Typical CV response of NaR-SAM-GNP-PPy-Pt electrode (a) $100 \mu \mathrm{M}$, (b) $200 \mu \mathrm{M}$, (c) $400 \mu \mathrm{M}$, (d) $700 \mu \mathrm{M}$ and (e) $1000 \mu \mathrm{M}$ of $\mathrm{NO}_{3}^{-}$in $0.1 \mathrm{M}$ PBS ( $\mathrm{pH} \mathrm{7.0)}$ at scan rate: $50 \mathrm{mV} \mathrm{s}^{-1}$ versus $\mathrm{Ag} / \mathrm{AgCl}$. (B) A linear calibration plot for the cathodic peak currents $I_{p c}$ versus $\left[\mathrm{NO}_{3}^{-}\right] / \mu \mathrm{M}$. $\left(I_{p c}=0.0624\left[\mathrm{NO}_{3}^{-}\right]+52.332, r^{2}=0.9837\right)$. Each point represents the average of three measurements.

levels may interfere in the electrochemical determination of $\mathrm{NO}_{3}^{-}$. When these interferences were added into the $0.1 \mathrm{M}$ PBS containing $500 \mu \mathrm{M} \mathrm{NO}_{3}^{-}$(Fig. 7), there were only slight changes observed. Also, the time versus current response of the biosensor for the addition of $500 \mu \mathrm{M}$

Table I. The electroanalytical properties of the $\mathrm{NO}_{3}^{-}$biosensor.

\begin{tabular}{lcccc}
\hline Electrodes & Linearity & Sensitivity & limit & Ref. \\
\hline $\mathrm{NaR} / \mathrm{MV}^{2+a}-\mathrm{PPy} / \mathrm{GCE}$ & $35 \mu \mathrm{M}-3 \mathrm{mM}$ & $13.8 \mathrm{~mA} / \mathrm{M}$ & $0.4 \mu \mathrm{M}$ & 24 \\
$\mathrm{NaR}^{\mathrm{N}} \mathrm{Nf}^{b} / \mathrm{MV}^{2+} / \mathrm{Au}^{c}$ & $20 \mu \mathrm{M}-250 \mu \mathrm{M}$ & - & $5 \mu \mathrm{M}$ & 36 \\
$\mathrm{PS}^{d} / \mathrm{NaR} / \mathrm{GCE}^{e}$ & $5 \mu \mathrm{M}-0.4 \mathrm{mM}$ & $60 \mathrm{~mA} / \mathrm{M}$ & $4.5 \mu \mathrm{M}$ & 37 \\
$\mathrm{NaR} / \mathrm{PPy} / \mathrm{Pt}$ & $100 \mu \mathrm{M}-5 \mathrm{mM}$ & - & $15 \mu \mathrm{M}$ & 38 \\
$\mathrm{NaR} / \mathrm{SAM} / \mathrm{GNP} / \mathrm{PPy} / \mathrm{Pt}$ & $1 \mu \mathrm{M}-1 \mathrm{mM}$ & $84.5 \mathrm{~mA} / \mathrm{M}$ & $0.5 \mu \mathrm{M}$ & Present \\
& & & & work \\
\hline
\end{tabular}

${ }^{a}$ Methyl viologen, ${ }^{b}$ Nafion, ${ }^{c}$ Gold, ${ }^{d}$ Phenosafranin, ${ }^{e}$ Glassy carbon electrode.

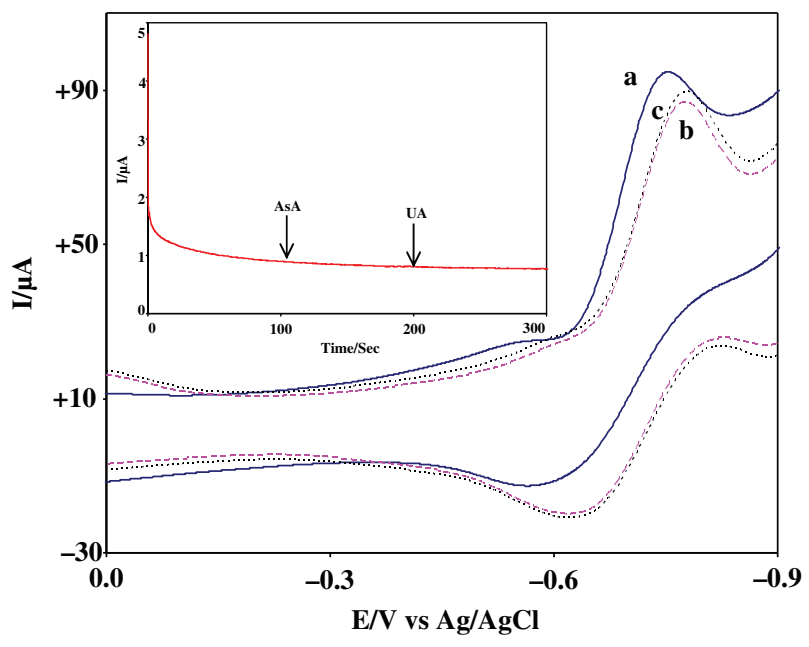

Fig. 7. Typical CV response of NaR-SAM-GNP-PPy-Pt electrode (a) $500 \mu \mathrm{M} \mathrm{NO}_{3}^{-}$, (b) $500 \mu \mathrm{M} \mathrm{NO}_{3}^{-}+500 \mu \mathrm{M}$ UA and (C) $500 \mu \mathrm{M}$ $\mathrm{NO}_{3}^{-}+500 \mu \mathrm{M}$ AsA in $0.1 \mathrm{M}$ PBS $(\mathrm{pH} 7.0)$ at scan rate: $50 \mathrm{mV} \mathrm{s}^{-1}$ versus $\mathrm{Ag} / \mathrm{AgCl}$. The chronoamperometric response of the NaR-SAMGNP-PPy-Pt electrode in $0.1 \mathrm{M}$ PBS containing $500 \mu \mathrm{M} \mathrm{NO}_{3}^{-}$in the presence of $500 \mu \mathrm{M}$ of AsA and UA (Inset of Fig. 7).

each of AsA and UA was studied chronoamperometrically (shown as inset in Fig. 7) and obtained no changes in the currents. For the stability and reproducibility test, cathodic responses for $\mathrm{NO}_{3}^{-}$were recorded three times daily and the current responses were found to be constant for one month, which holds relatively longer stability than other $\mathrm{NO}_{3}^{-}$biosensors.

\subsection{Determination of $\mathrm{NO}_{3}^{-}$Levels in Beetroot Supplement}

Beetroot juice, which contains a high level of nitrate, substantially decreases blood pressure (BP) levels, inhibits platelet aggregation and prevents ischemiainduced endothelial dysfunction [www.sciencedaily.com]. In this study, we attempted to measure the $\mathrm{NO}_{3}^{-}$level present in the beetroot supplement using our highly sensitive $\mathrm{NO}_{3}^{-}$biosensor. The cathodic peak current of the NaR-SAM-GNP-PPy-Pt electrode obtained for the beetroot juice was compared with the linear calibration curve (Fig. 6(B)) reveals that the concentration of $\mathrm{NO}_{3}^{-}$is present in the range of $600 \pm 12 \mu \mathrm{M}$. Further, this result was validated with the standard griess method and found that $602 \pm 12.0 \mu \mathrm{M}$ of $\mathrm{NO}_{3}^{-}$is present. In order to make sure these results, the same measurement was carried out thrice

Table II. Comparison of the present $\mathrm{NO}_{3}^{-}$biosensor along with the standard griess method for the measurement of $\mathrm{NO}_{3}^{-}$in the beetroot juice.

\begin{tabular}{lcc}
\hline $\begin{array}{l}\text { No. of } \\
\text { experiments }\end{array}$ & $\begin{array}{c}\text { Nitrate conc. by } \\
\text { griess method }(\mu \mathrm{M})\end{array}$ & $\begin{array}{c}\text { Nitrate conc. } \\
\text { by biosensor }(\mu \mathrm{M})\end{array}$ \\
\hline 01 & $593 \pm 11.8$ & $590 \pm 11.8$ \\
02 & $612 \pm 12.2$ & $610 \pm 12.2$ \\
03 & $601 \pm 12.0$ & $600 \pm 12.0$ \\
\hline
\end{tabular}




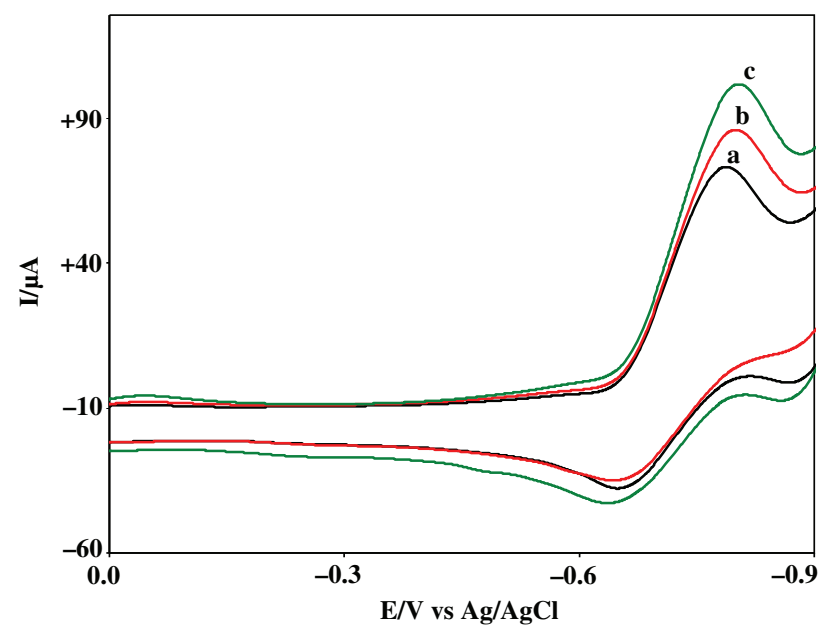

Fig. 8. Typical electrochemical response of the NaR-SAM-GNP-PPyPt electrode for MCF-7 cells treated with (a) control, (b) 50 ng LPS and (c) $100 \mathrm{ng}$ LPS in $0.1 \mathrm{M}$ PBS (pH 7.0) at scan rate:50 $\mathrm{mV} \mathrm{s}^{-1}$ versus $\mathrm{Ag} / \mathrm{AgCl}$.

and the results obtained using both the methods were compared as shown in Table II.

\subsection{Measurement of $\mathrm{NO}_{3}^{-}$Release from LPS Treated MCF-7 Human Breast Cancer Cells}

Earlier studies reported that the $\mathrm{NO}_{3}$, stable end product of $\mathrm{NO}, \mathrm{NO}_{2}^{-}$is generated by breast cancer cells when exposed to LPS. ${ }^{9}$ We have estimated here the $\mathrm{NO}_{3}^{-}$release from LPS treated MCF-7 cells using the developed $\mathrm{NO}_{3}^{-}$biosensor. After $24 \mathrm{hrs}$ stimulation by $50 \mathrm{ng}$ LPS the cathodic peak current at $-0.76 \mathrm{~V}$ clearly increased compared to control and found that the concentration of $\mathrm{NO}_{3}^{-}$released from the MCF-7 cells is $86.5 \pm 1.73 \mu \mathrm{M}$ (Fig. 8). The cathodic peak current of the $100 \mathrm{ng}$ LPS stimulation was also investigated and found that $200.4 \pm 4.0 \mu \mathrm{M}$ of $\mathrm{NO}_{3}^{-}$ was released. Thus LPS dose dependently stimulated $\mathrm{NO}_{3}^{-}$ release from the cancer cells. The concentrations of the $\mathrm{NO}_{3}^{-}$levels generated from the cancer cells determined were in agreement with the reference method. ${ }^{9}$

\section{CONCLUSION}

A highly sensitive and selective $\mathrm{NO}_{3}^{-}$biosensor in which $\mathrm{NaR}$ was covalently linked to the SAM of cysteine on GNP in PPy matrix has been reported. The efficient combination of SAM on GNP in microporous PPy matrix enhanced the effective loading and electrocatalytic activities of $\mathrm{NaR}$ without their denaturation. The direct electron transfer facilitated between the electrode and the active site of the NaR provided a highly sensitive method for the determination of $\mathrm{NO}_{3}^{-}$. The fabricated $\mathrm{NO}_{3}^{-}$biosensor also exhibited good reproducibility and long term stability. This $\mathrm{NO}_{3}^{-}$biosensor was further applied to the $\mathrm{NO}_{3}^{-}$ determination in beetroot juice samples and human breast cancer cells.

\section{Abbreviations}

$\begin{array}{ll}\text { AsA } & \text { Ascorbic acid } \\ \mathrm{CV} & \text { Cyclic voltammetery } \\ \mathrm{GNP} & \text { Gold nanoparticles } \\ \mathrm{HAuCl}{ }_{4} \cdot 3 \mathrm{H}_{2} \mathrm{O} & \text { Chloroauric acid trihydrate } \\ \mathrm{LPS} & \text { Lipopolysaccharide } \\ \mathrm{NaR} & \text { Nitrate reductase } \\ \mathrm{NO} & \text { Nitric oxide } \\ \mathrm{NO}_{2}^{-} & \text {Nitrite } \\ \mathrm{NO}_{3}^{-} & \text {Nitrate } \\ \mathrm{PBS} & \text { Phosphate buffer solution } \\ \mathrm{PPy} & \text { Polypyrrole } \\ \mathrm{Pt} & \text { Platinum } \\ \mathrm{SAM} & \text { Self-assembled monolayer } \\ \mathrm{SEM} & \text { Scanning electron microscopy } \\ \mathrm{UA} & \text { Uric acid }\end{array}$

Acknowledgments: This work was supported by the DIPAS-DRDO, New Delhi, India (Grant No. TC/341/Task-165(CKK)/DIPAS/2010), and the Managing Board of Virudhunagar Hindu Nadar's Senthikumara Nadar College, Virudhunagar, Tamil Nadu, India. Ramanujan Fellowship to KS from DST and Senior Research Fellowship to AKK from CSIR, India are greatly acknowledged.

\section{References and Notes}

1. S. R. Tannenbaum and P. Correa, Nature 317, 675 (1985).

2. J. O. Lundberg, E. Weitzberg, and M. T. Gladwin, Nat. Rev. Drug Discov. 7, 156 (2008).

3. A. J. Webb et al., Hypertension 51, 784 (2008).

4. F. J. Larsen, E. Weitzberg, J. O. Lundberg, and B. Ekblom, Acta Physiol. (Oxf) 191, 59 (2007).

5. J. O. Lundberg et al., Nat. Chem. Biol. 5, 865 (2009).

6. A. A. Kenjale et al., J. Appl. Physiol. 110, 1582 (2011).

7. K. J. Joshipura et al., Ann. Intern. Med. 134, 1106 (2001).

8. F. L. Crowe et al., Eur. Heart J. 32, 1235 (2011).

9. S. Kotamraju, C. L. Willams, and B. Kalyanaraman, Cancer Res. 67, 7386 (2007)

10. N. Beda and A. Nedospasov, Nitric Oxide 13, 93 (2005).

11. Y. Xuan-Feng, Z. Zhi-Qi, and Y. Hong-Tao, Talanta 62, 97 (2004).

12. J. W. Aylotta, D. J. Richardson, and D. A. Russell, Analyst 122, 70 (1997).

13. R. T. Masserini and K. A. Fanning, Mar. Chem. 68, 323 (2000).

14. J. R. E. Thabano, D. Abongo, and G. M. Sawula, J. Chromatogr. A 1045, 153 (2004).

15. S. J. R. Prabakar and S. S. Narayanan, Electroanalysis 21, 1481 (2009).

16. S. Rajesh, U. S. E. Arivudainambi, S. Raja Singh, A. Rajendran, S. Kotamraju, and C. Karunakaran, Sens. Lett. 8, 1 (2010).

17. S. Rajesh, A. Koteswararao, K. Bhargava, G. Ilavazhagan, S. Kotamraju, and C. Karunakaran, Biosensors Bioelec. 26, 689 (2010).

18. P. Dharmapandian, S. Rajesh, S. Rajasingh, A. Rajendran, and C. Karunakaran, Sens. Actuators B 148, 17 (2010).

19. L. M. Moretto, P. Ugo, M. Zanata, P. Guerriero, and C. R. Martin, Anal. Chem. 70, 2163 (1998). 
20. M. Badea, A. Amine, G. Palleschi, D. Moscone, G. Volpe, and A. Curulli, J. Electroanal. Chem. 509, 66 (2001).

21. D. Kirstein, L. Kirstein, F. Scheller, H. Borcherding, J. Ronner, S. Dieckmann, and P. Steinrucke, J. Electroanal. Chem. 474, 43 (1999).

22. S. Cosnier, C. Innocent, and Y. Jouannea, Anal. Chem. 66, 3198 (1994).

23. J. C. M. Gamboa, R. C. Pena, T. R. L. C. Paixao, and M. Bertotti, Talanta 80, 581 (2009).

24. M. T. D. Groot and M. T. M. Koper, J. Electroanal. Chem. 562, 81 (2004).

25. D. Quan, J. H. Shim, J. D. Kim, H. S. Park, G. S. Cha, and H. Nam, Anal. Chem. 77, 4467 (2005).

26. S. Reiter, K. Habermuller, and W. Schuhmann, Sens. Actuators B 79, 150 (2001).

27. T. Ahuja, I. Ahmad Mir, D. Kumar, and Rajesh, Sens. Actuators B 134,140 (2008)
28. J. Manso, M. L. Mena, P. Y. Sedeno, and J. M. Pingarron, Anal. Biochem. 375, 345 (2008)

29. P. Raveendran, J. Fu, and S. L. Wallen, Green Chem. 8, 34 (2006).

30. I. Becerik, and F. Kadirgan, Elec. Chim. Acta 42, 283 (1997).

31. V. Tsakova, L. Sabbatinia, and P. G. Zambonin, Mater. Chem 11, 1434 (2001)

32. L. Xiaofeng, C. Danming, C. Jingyu, Z. Wanjin, and W. Yen, Mater Lett. 60, 2851 (2006).

33. R. Zhu, G. Li, and G. Huang, Mater. Corros. 60, 34 (2009).

34. S. E. Moulton, J. N. Barisci, A. Bath, R. Stella, and G. G. Wallac, Elec. Chim. Acta 49, 4223 (2004).

35. A. Mortari, Ph.D Thesis, Lund University (2008)

36. X. Wang, S. V. Dzyadevych, J. M. Chovelon, N. J. Renault, L. Chen, S. Xia, and J. Zhao, Talanta 69, 450 (2006).

37. N. F. Ferreyra and V. M. Sol, Bioelectrochem. 64, 61 (2004).

38. M. Sohail and S. B. Adeloju, Sens. Actuators $B$ 133, 333 (2008). 